week, and least fatal in the $24^{\text {th }}$ week. Scarlatina showed a tendency to increase when the mean temperature rose much above 50 degrees, while a fall of mean temperature below this point in autumn checked the further rise of the mortality. Why, then, if a fall of temperature below 53 degrees tended to arrest this disease, does it happen that the mortality is undoubtedly so high in winter? In Dublin it continues very high until the $9^{\text {th }}$ week, and high until the I $^{\text {th }}$ week of the year. Here we are brought face to face with one of the most important factors in all sanitary problems-namely, overcrowding. Scarlatina is not only one of the most contagious diseases in existence, but the materies morli - whatever it may be--remains in an active state for a lengthened period. Hence the difficulty of disinfecting the bedchambers of scarla. tina patients. In these facts is contained the solution of the problem. As winter approaches, the instinct is to diminish the sources of ventilation, and among our poorer fellow-citizens-badly clothed and with inadequate supplies of fuel-unrestrained freedom is given to this instinct, but with most deplorable consequences. Every chink and crevice through which the outer air might gain access to the overcrowded tenement is engerly sought out and effectually closed. It is under these circumstances that scarlatina, favoured by the high and unwholesome temperature of the rooms, runs like wildfire among many families in the poorer parts of the city. But the mischief does not end here, for the contagious powers of the disease are called into full play, and the richer and more affluent quarters of the city suffer in their turn from this dire pestilence. We must not forget, also, that in winter the throat complications of scarlatina are likely to be more severe and fatal than in summer and autumn.

Fever in Dublin may well be described as both an epidemic and an endemic disease. In 1865 and 1866 it prevailed as an epidemic disease, but it is never absent from this city, and so its title to be considered an endemic disease also is clearly established. The first thing to be noticed with regard to fever is its remarkable tendency to prevail in the first quarter of the year. Fever appears to depend especially on the weather. In the consideration of fever it would be desirable to isolate two forms of the disease-typhus and typhoid, or enteric, feverand with the former we may, for this investigation, group the so-called continued fever. Fever in general has proved most fatal in the 3 rd and 4 th weeks of the year, and least fatal in the 28 th and 29th weeks. The disease was most severe about the period of the greatest cold, and least so early in July. It again appeared to become very fatal in autumn, when the mean temperature fell below 54 degrees. The mortality continued to rise with the falling temperature until January and Feloruary were past. Early in March the mortality declined, but rose again at the beginning of May, coincidentally, it would seem, with a lower humidity. The decline was then very rapid, and the minimum was reached in July, and the first half of August. A temperature higher than 54 degrees seems to have a controlling influence on the prevalence of fever, whilst temperatures below 54 degrees seem to favour its development. With regard to typhoid fever, a striking increase was to be noticed in its percentage amount towards the close of the year; whilst, on the other hand, the highest percentage of typhus fever occurred in the seasons of winter, spring, and early summer. The reason for all this is not far to seek. Typhus is intimately related to overcrowding, and bronchial or thoracic affections are amongst its most frequent complications. Typhoid fever is connected with a specific contamination of air or water by sewage matter, and its secondary phenomena are developed generally in connection with the digestive system. Hence a greater prevalence of this form of the disease was to be looked for in the warmer seasons, and more particularly at a time when the first autumn rains had washed into drinking wells, and other sources of water-supply, the decomposing matter which had hitherto remained innocuous.

All these considerations, novel and important as they are, form but one chapter in the study of the relations between meteorology and health. Among other cognate inquiries I would particularise only the works of Dr. Angus Smith on Air and Rain, of Dr. Cornelius Fox on Ozone and Antozone, and of Professor Buhl, of Munich, on the Relation between Typhoid Fiver and the Height of the Underground, or Siubsoil, Water. The Influence of Light on Hialth, first shadowed forth by our great countryman, Dr. Graves, has been ably handled by Dr. Forbes Winslow. In his essay on the Influence of Light, Dr. Graves wrote this eloquent and touching passage :- "I need not observe that the flowers and leaves of all plants court the light. Indeed, this tendency is manifested sometimes in a very curious manner. This is exemplified in the various flowers which adorn the dark and comfortless abodes of the tradesmen in the Liberties of Dublin. These poor creatures (for however poor the being is, or however confined by the nature of his employment, he never forgets the green freshness and living loveliness of nature) delight in flowers and birds; and in their windows will frequently be seen a geranium, almost as sickly as its owner, turning its lank and stunted leaves with unvarying constancy towards the light."

"Die Pflanze selbst kehrt freudig sich zum Lichte."-Schillir.

In conclusion, as to the practical bearing of these investigations, we find that some of the diseases we have been considering tend to prevail in the warm seasons of the year-others in the cooler seasons. There is, further, only too good reason for believing that the mortality of many diseases included even in the former class, is increased by overcrowding and its attendant evils, while the influence for evil of this flagrant breach of sanitary law on winter maladies is almost beyond belief. Overcrowding, alas! is but another name for poverty, and poverty means-want of fuel, deficient food, deficient clothing. Is it not incumbent upon us, sanitary reformers and pioneers of preventive medicine, to obviate, so far as lies in our power, the ill-effects of cold? In the case of scarlatina, again, and other infectious diseases, let refuges be provided for the still healthy members of families stricken with disease. As regards summer maladies, too, the providing of wholesome food, the interdicting of unripe fruit and putrid vegetables, the free use of suitable disinfectants in sewers and latrines, and, above all, a pure water supply, will have the happiest results. Of all the diseases, fever, however, is, perhaps, the most preventable, depending, as it does, so largely on overcrowding and bad ventilation. How are we to deal with it from a preventive point of view? The English Registrar-General said on this point:- "Fire is a necessity of life in this climate, and a warm hearth mitigates the severity of winter. Fire is as much required by the poor as by the rich, and a tax on coals, like a tax on salt, presses with undue severity on people of small means." And so it is-our poorer fellow-citizens have to do battle with snow and ice, hail and tempest. Their weapons of defence in this otherwise unequal warfare must be raiment, food, and warmth. Lo, there, on the journey of life, lies the wounded, the helpless wayfarer, cold, and naked and hungry. Be you the good Samaritans.

\section{A VISIT TO A LEPER-VILLAGE.}

\section{By ARTHUR LEARED, M.D., F.R.C.P.,} Senior Physician to the Great Northern Hospital.

THE leper-village El Hara is just outside the Donkkela Gate of the city of Morocco. It is of considerable size, and fenced in with earthen walls. There is only one entrance, close to which is the sanctuary of the patron saint, Seedi Ben Nor. On account of this proximity, an objection was made to my going into the village; but a number of the inhabitants soon made their appearance, and were friendly and com. municative. Many of them were well developed, well nourished people; and some showed no outward sign of disease. They form a community apart, having a mosque, a prison, and a market of their own. They also cultivate land, and buy and sell like other people. The whole population was stated to be two hundred. Many of them come from long distances-from Haha, from Suse, and even from the Sahara. Many of them are negroes. Some have been resident for thirty years, and there are a few very old people amongst them. There is a Jewish quarter, with a synagogue; but, although there were five Jew residents a few years ago, there was not one at the time of my visit.

Notwithstanding this separation of the lever population, the general opinion amongst the Moors is that leprosy is not contagious. They not only go into the leper-village freely, but will eat and drink, and even sleep in the same room, with those affected by the disease. The lepers themselves are allowed to enter, but not to stay in the city. About the city gate we saw many wretched creatures, in whom the disease was so far advanced that begging, which is vociferously conducted, was their only resource.

In the group which surrounded us at the village, one thing which particularly struck me was alteration of the voice. Many spoke with that characteristic huskiness which denotes that the disease has attacked the windpipe. In some cases, a tubercle or two on the forehead or at the side of the nose was all that rendered it imperative for them to separate from the healthy. One boy had lost the fingers and thumb of his left hand; the little finger of his right hand had also dis. appeared, and the remaining fingers and the thumb were crippled and useless. Several had lost toes to a greater or less extent. In some cases, there were foul unhealthy ulcers; and in one such instance that I examined, the thick skin of the back of one heel had the appearance of having had a large piece punched out. No application seems to be made to the sores, nor do they try any medicines. Washing at the 
sacred well of the saint-house, which is thought to possess virtues, is all that is practised.

One of the lepers, an intelligent Moor, told me that there are seven kinds of leprosy; and the fact that he was surrounded by fellow-lepers, who at times interrupted his description in order to set him right, proved that the division is well recognised amongst them. The first, he said, is the kind which cripples the hands; the second is the tubercular form; the third, that in which the skin is affected, and the hair of the head and the beard fall off ; the fourth, that in which the fingers and toes are destroyed; the fifth, that in which the skin becomes like the skin of a fish; the sixth, that in which cough is a prominent symptom, and also severe pains in the chest of a shooting nature; the skin is not much affected; but the disease is accompanied by so much debility, that the patient can at last hardly lift a pound weight; and, when this happens, the patient soon dies. The seventh kind destroys or greatly impairs the sexual power, and in this the skin is also affected. If persons with this form of the disease have children, they are weakly, but the children are seldom affected. It was added that, in the other kinds of leprosy, the sexual functions are intact; and that those who have lost fingers are apt to be salacious.

It is obvious that, in this minute subdivision, mere stages are regarded as different forms of the same disease; and also that certain symptoms have been regarded in the same way. No doubt some of the conclusions are crude and erroneous; yet, as they have been arrived at by the lepers themselves, they seemed to me worthy of notice.

There are more women in this village than men, but this is perhaps due to polygamy. The children of the leprous parents are sometimes, but not usually, diseased. The inhabitants enjoy no exemption from fever or other diseases. The causes assigned for leprosy were overwork and drinking cold water when perspiring, and also that God sends it to punish people for their crimes.

Leprosy is called "Jeddem" by the Moors; and the extensive use in cookery of argan-oil, expressed from the seeds of Argania Sideroxylen, is supposed by many to cause the disease; but there seems no good reason for this conclusion. Lepers are met in small parties in every part of the empire. They may be known at a distance by a straw hat with a wide brim, which they are compelled to wear, in order to distinguish them from those free from the disease. When the large number of the Jewish population is taken into account, their exemption is remarkable; but, as stated previously, they are not altogether exempt. I was consulted in the city of Morocco by a young Jew of the better class, who was suffering from the scaly form of the disease.

\section{CASE OF DISSECTING RUPTURE OF THE HEART.}

\section{BY J. H I G A M HIL L, F.R.C.S.,} Medical Officer to St. Pancras Workhouse.

THE pathological interest of the following case induces me to place it upon record.

S. G., aged 65, a woman of spare habit of body, was on December 6 th, while in her usual health, suddenly seized with an acute pain in the region of the heart, followed by considerable dyspnœa and vomiting. She was removed to bed, and my attention was called to her. I fourd her slightly collapsed, with cold extremities, breathing with diffculty, and inclined to vomit. She still complained of pain in the region of the heart. On examination, I found that the cardiac action was irregular and very weak ; there was, however, no murmur. She was ordered to have some brandy and Seltzer water, also a mustardplaster over the heart, and a hot-water bottle to her feet. Under this treatment she rallied considerably ; her circulation improved, and the dyspnœa, sickness, and pain were relieved. She continued in this ap parently improved condition for about twenty-four hours, when death suddenly took place, consciousness being retained to the last.

On making a post mortim examination, the pericardium was found to be full of blood, which was discovered to have escaped from the interior of the heart through a small rupture in the right auricle. The left side of the heart was considerably hypertrophied, the right side much atrophied, and the cardiac tissue generally in a state of fatty degeneration. There was no valvular disease present.

The chief point of interest in the case is, that the blood, in escaping, had not made a direct passage through the wall of the auricle, but, having broken through the endocardium and a portion of the degenerated muscular structure, had then dissected the wall of the heart for a considerable distance around into two distinct layers, and finally had broken through the outer layer into the cavity of the pericardium.
Both openings were small-the external one two inches nearer the superior vena cava than the internal one. The interspace made by this dissecting process in the wall of the heart was filled with a layer of quite recently coagulated blood. The lungs were healthy, but the liver and kidneys were in a state of fatty degeneration.

\section{AN ÆSTHETICS.}

\section{THE ADMINISTRATION OF CHLOROFORM.}

Dr. ERnest Sansom, Physician to the Royal Hospital for Diseases of the Chest, writes as follows.

There are many points in the paper on the Adninistration of Chloro. form, by Dr. Henry Marshall, in the BRITISH MEDICAL JOURNAL of March I5th, 1873, with which I entirely agree. I believe that the occurrence of panic is apt to make us overestimate the danger of chloroformisation ; that many of the deaths attributed to the anæsthetic may have been really due to shock; and that the time has not yet arrived at which we can point to any agent capable of inducing profound narcotism as absolutely free from danger to life. There is one deduction, however, of Dr. Marshall's from which I differ toto calo, because I think it endorses a widely spread but erroneous view.

The towel or handkerchief, as an article for the administration of chloroform, Dr. Marshall extols for convenience as well as for insuring a free admixture with air. He concludes, from Mr. Lister's experiments, that "when the towel is used, the amount of chloroform-vapour does not exceed four-and-a-half per cent. of the air inspired, even im. mediately after fresh chloroform has been added; but the average percentage must be less than four per cent." To this conclusion I emphatically demur. No one can have a higher appreciation than myself of the valuable contributions of Mr. Lister to the cause of science, but I believe that in this particular instance he has been victimised by imperfect experimentation. The method adopted (which I will not quote at length ; it may be read in the article on Anæsthetics in Holmes's System of Surgery, vol. iii, p. 97) seems to me to be beset with fallacies: and the writer of an exhaustive review concerning anæsthesia, in the American Fournal of Medical Science, January 1867 , p. 176 , says with regard to it: "We think common sense will negative any amount of such experimentation."

I have taken some pains to investigate this point, and the conclu. sions which I derived from my experiments tend to show that the percentage of chloroform-vapour capable of being inspired when the anxsthetic has been poured upon a piece of lint has been greatly underestimated. When $76.5,38.25,25.5,12.75$, and 6.375 grains respectively of pure chloroform were poured upon a piece of lint, and 100 cubic inches of air, at a temperature of from 60 to 64 deg. Fahr., were passed over it in each instance, the resultant atmosphere contained 9.9, 8.5, 6.9, and 4.3 per cent. of chloroform-vapour (Transactions of the Obstetrical Socicty of London, vol. x, p. 136). When little more than a drachm, therefore, of chloroform is poured upon lint at ordinary temperature, a patient may inhale an atmosphere containing more than nine per cent. - a dose certainly not free from danger.

I have never seen reason to change the opinion I long ago ex. pressed, that a part of the mortality from chloroform is due to the inhalation of an overcharged atmosphere, when the towel or handkerchief is employed, with insufficient means of admixture with air ; and I believe that the tendency of investigation has been to show that the chief mode by which the anæsthetic accomplishes its fatal effect is by paralysing the heart.

SULPHURIC ETHER $A S$ AN ANESTHETIC.

Dr. John H. PACKARD, one of the surgeons to the Episcopal Hospital, Philadelphia, United States, writes as follows.

The reaction which seems to be taking place, or rather to have already taken place, in England in favour of sulphuric ether as an anæsthetic, has given me, as it has many other American physicians, sincere satisfaction; and, in the hope of aiding what I cannot but consider a good cause, I venture to offer some facts and considerations to those who are investigating the subject. During the past twenty years, the use of anesthetics has been a matter of constant observation with me, either in my own hands or in those of my professional associates. Until t 864, my custom was to employ ether or chloroform indifferently: two cases then occurred, in one of which death from the latter agent was only averted by means of galvanism, while in the other it actually took place.*

* These cases were reported in the American Fournal Medical Scicnces for January 1865, p. 271 . 